\title{
The Development of Biocatalysis as a Tool for Drug Discovery
}

\author{
Jenny Schwarz ${ }^{\S a}$, Katrin Rosenthalsa, Radka Snajdrova ${ }^{b}$, Matthias Kittelmann ${ }^{c}$, and Stephan Lütz ${ }^{\star a}$
}

In memoriam Prof. Dr. O. Ghisalba (1946-2018)

\begin{abstract}
Enzymes are versatile biocatalysts capable of performing selective reactions. The advantages of enzymes in comparison to classical chemistry including chemical catalysts are the generally milder process conditions and avoidance of harmful reactants. Their high selectivity and specificity are especially beneficial for the enzymatic synthesis of new products with potential applications in drug research. Therefore, in the past decades, the utilization of isolated enzymes or whole-cell biocatalysts has spread through a growing number of biotechnological industries. The applications comprise the production of chiral building blocks for the pharmaceutical and fine chemical industry, the enzymatic synthesis of drug metabolites for testing of toxicity, function, biological activity, degradation and the production of biocatalytically modified natural products, which all play a role in drug discovery. Especially Oreste Ghisalba's contributions, which paved the way for the industrial use of enzymes, will be considered in this review.
\end{abstract}

Keywords: Biocatalysis · Chiral building blocks · Drug metabolites · Natural product modifications · Pharmacological activity

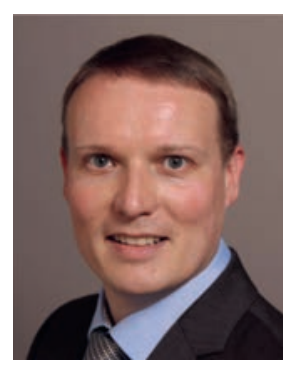

Stephan Lütz holds the chair for Bioprocess Engineering at TU Dortmund University since 2016. He studied chemistry in Bonn, where he also completed his PhD studies in 2004. He started his independent research at the Institute of Biotechnology in Jülich as leader of the technical biocatalysis group. From 2009 till 2016 he led the Bioreactions group at Novartis Pharma AG as successor of Oreste Ghisalba. He obtained his habilitation in biochemistry and was a lecturer at the Universities of Bonn and Basel during this time. His research focusses on biotechnological and biocatalytic process development.

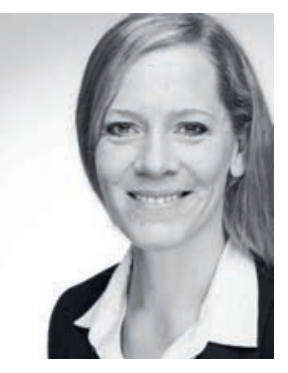

Katrin Rosenthal focuses with her research group on biotransformations and microbioreaction engineering at the chair for Bioprocess Engineering at TU Dortmund University since 2018. She studied biochemical engineering in Dortmund, where she also completed her $\mathrm{PhD}$ studies in 2016 on single-cell analysis of industrially relevant microorganisms. In 2016 she joined the chair for Bioprocess Engineering of Stephan Lütz as postdoc. Her research comprises cell-free protein synthesis, enzyme reaction cascades, microfluidics, as well as biocatalytic process development.

${ }^{*}$ Correspondence: Prof. Dr. S. Lütz ${ }^{\mathrm{a}}$, E-mail: stephan.luetz@tu-dortmund.de aChair for Bioprocess Engineering, TU Dortmund University, Emil-Figge-Str. 66, D-44227 Dortmund, Germany; ' $G$ Gobal Discovery Chemistry, Novartis Pharma AG, Lichtstrasse, $\mathrm{CH}-4056$ Basel, Switzerland; Institutes for BioMedical Research, Novartis Pharma AG, Lichtstrasse, $\mathrm{CH}-4056$ Basel, Switzerland; `scontributed equally

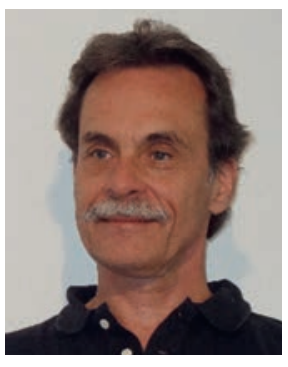

Matthias Kittelmann studied microbiology/biochemistry in Bonn (Germany) and received his diploma in 1984 on the microbiota of industrial vinegar fermentations. In his $\mathrm{PhD}(1989)$ at the Institute for Enzyme Technology in the Research Center Jülich (Germany) with Prof. M.-R. Kula he identified a new microbial enzyme applicable for amino acid and dipeptide synthesis. In 1989 he joined the Bioreactions group of CibaGeigy AG/Novartis AG in Basel (Switzerland), which was under the lead of Oreste Ghisalba until 2008. In the first years Matthias $\mathrm{K}$. worked in the field of enzymatic carbohydrate chemistry, on identifying novel, biocatalytically useful enzymes and on classical microbial biotransformation. Around 2000, his focus shifted towards the biocatalytic synthesis of drug metabolites. Since 2018 he is in retirement.

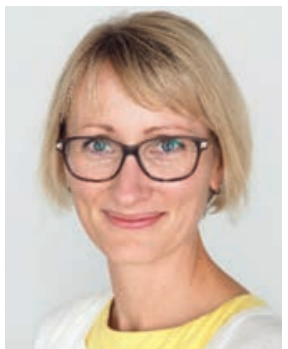

Radka Snajdrova obtained her PhD from Vienna University of Technology in 2007. She received an Erwin-Schrödinger Fellowship and spent one year of postdoctoral study at York University in the UK. In 2009, Radka moved to University of Greifswald, Germany as a senior postdoctoral fellow. In 2010, she transitioned to industry with a one-year role at a lab focused on supporting chemists at GSK to take advantage of biocatalytic technologies (Novacta), prior to directly joining Chemical Process Development at GSK, UK as Project leader responsible for the development and implementation of new biocatalytic technology in both pre- and post-commercialization routes. Since Dec 2016, Radka is leading the Bioreactions group in Global Discovery Chemistry at Novartis Institute for Biomedical Research in Basel. 


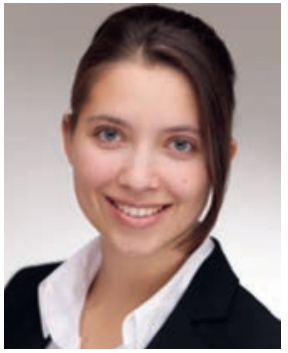

Jenny Schwarz studied biochemical engineering at TU Dortmund University. In 2016, she finished her master's degree with the thesis 'Experimental Investigation of In Situ Rhamnolipid Adsorption Coupled with the Fermentation of Pseudomonas putida KT2440' at the lab of Bioprocess Engineering with Rolf Wichmann. Since 2016, she is working on her $\mathrm{PhD}$ thesis at the chair of Bioprocess Engineering with Stephan Lütz at TU Dortmund University. Her research focuses on the activation of silent secondary metabolite gene clusters in bacteria through variation of culture conditions.

\section{Introduction}

The field of biocatalysis has developed tremendously during the last decades. This can be seen in the ever-growing number of selective organic syntheses based on the use of whole-cells or enzymes, the development of enzyme engineering methods as well as the genome-based studies into the biosynthesis of natural products. In addition, a growing number of industries uses biotechnological approaches for their purposes. ${ }^{[1]}$ The applications include a vast variety of enzymes and reactions, e.g. in laundry detergents, for food processing or in the production of basic chemicals and pharmaceutical compounds. ${ }^{[2]}$ The progress in some of these applications reflects the development of the field of biocatalysis as a whole.

The main drivers of biocatalysis development are based on the availability of three-dimensional enzyme structures, the invention of various mutagenesis technologies, up to the possibilities of de novo and in silico enzyme designs (Fig. 1). ${ }^{[3]}$ Not surprisingly, when Oreste Ghisalba started his research at CibaGeigy's central laboratories in the 1970s the work focused on using wild-type organisms and natural enzymes. This resulted in a number of syntheses for chiral building blocks, some of them based on proprietary enzymes. Today, it is common that an originally identified enzyme is optimized by protein engineering in order to adapt its properties to feasible process conditions and to explore novel reactions. ${ }^{[4]}$ First approaches were developed in the 1970s with genetic engineering tools enabling structure-guided protein engineering. Later, directed evolution technologies were developed mimicking the Darwinian principles of natural selection. By incorporating bioinformatics tools and strategies for statistical analysis, such as protein sequence activity relationship (ProSAR), the process of identify- ing individual mutations leading to improved biocatalysts was significantly accelerated. ${ }^{[5]}$ Nowadays, the application of nextgeneration sequencing technologies enormously increased the sequencing capacity and therefore the number of available gene sequences with great potential for the discovery of novel enzymes.

In most pharmaceutical companies, biocatalysis has been successfully applied for the development of greener production routes. Hence, the use of enzymatic and whole-cell biotransformations is much more common in drug development than in medicinal chemistry. This article will explore areas where biocatalysis can make an impact on drug discovery and how technologies have developed for this purpose over time from the discovery of proprietary enzymes to customized synthesis tools obtained from consortia projects. The application for the modification of natural products and the biocatalytic decoration of synthetic lead structures will also be discussed. A particular emphasis will be given to the contributions of Oreste Ghisalba in this field and, in consequence, of the Novartis Bioreactions group, which was headed by him from 1982-2008.

\section{Novel Chiral Building Blocks and Reagents for Pharmacological Applications}

Chiral building blocks are important for drug discovery and pharmaceutical production processes because almost all drug targets require matching chirality. In the realm of chiral building blocks, the contributions of $\mathrm{O}$. Ghisalba in the areas of nonproteinogenic amino acids, chiral amines and pure inositol-phosphates will be discussed.

\subsection{Non-proteinogenic Amino Acids}

Non-proteinogenic amino acids are amino acids that are not incorporated into natural proteins. They are widely found in nature and are often precursors, analogs or metabolic intermediates of proteinogenic amino acids. Non-proteinogenic amino acids have diverse physiological functions such as regulatory functions within metabolic cycles or as secondary metabolites. Furthermore, some non-proteinogenic amino acids exhibit pharmacological properties. Many of them are synthesized with chemo- or semisynthetic methods; however, chemo-synthesized amino acids are usually a racemic mixture of D- and L-amino acids. Only a few non-proteinogenic amino acids can be synthesized using natural biosynthetic pathways. Alternatively, enzymatic conversions of amino acid precursors can be applied to obtain optically pure products.

\section{Natural enzymes Genetic engineering Directed evolution Bioinformatics Next generation sequencing}
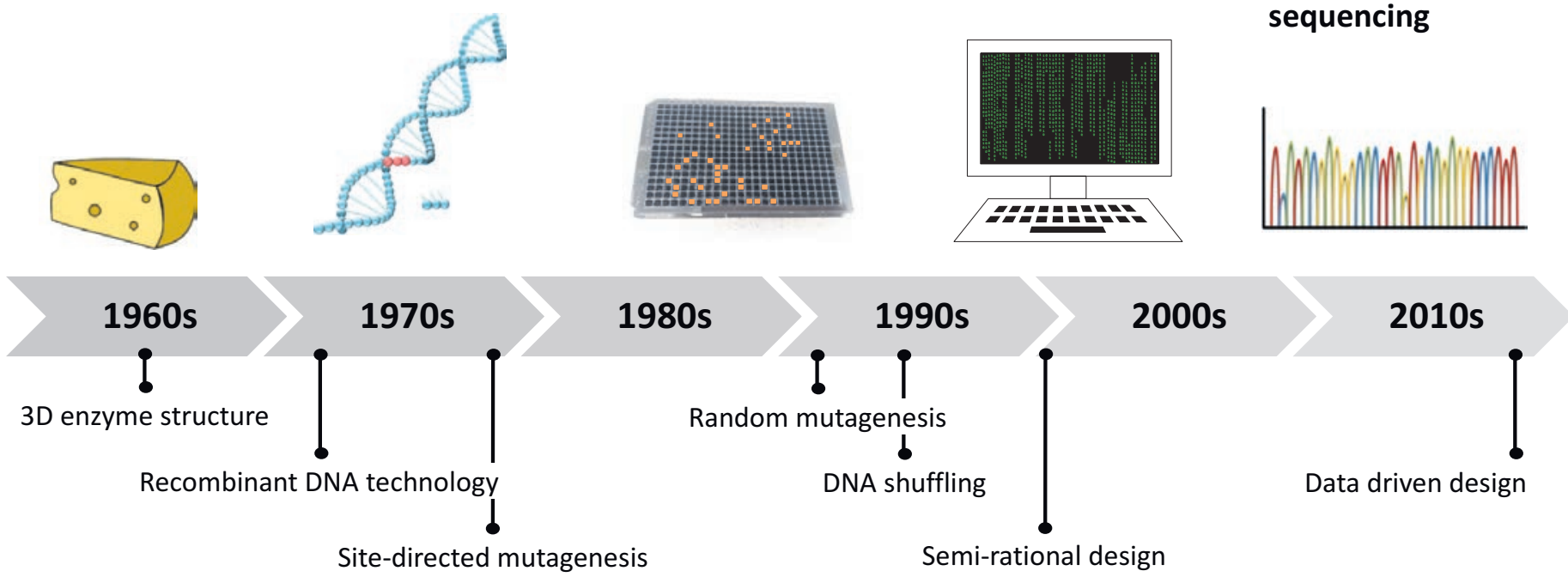

Fig. 1. Drivers of biocatalysis development over the last decades. ${ }^{[3]}$ 
Oreste Ghisalba contributed to the development of the synthesis of D-tert-leucine by enzymatic hydrolysis of ( \pm )- $\mathrm{N}$-acetyl-tertleucine chloroethyl ester as shown in Scheme 1.66] Optically active tert-leucine and derivatives are valuable precursor molecules for the synthesis of chiral auxiliaries and as building blocks for drugs. While an industrial scale process existed for L-tert-leucine production by enantioselective reductive amination using L-leucine dehydrogenase, ${ }^{[7]}$ no economically feasible manufacturing method for D-tert-leucine was available in those days. ${ }^{[8]}$ In order to develop novel synthesis routes, 45 enzymes were tested on their hydrolytic activity towards methyl ester. The protease from Bacillus licheniformis (Alkalase ${ }^{\circledR}$, Novo Nordisk) had the highest activity and was used in a preparative experiment to produce $77 \mathrm{~g}$ D-tert-leucine. The (dynamic kinetic) resolution route was successfully scaled up to the multi-kg level. [6]

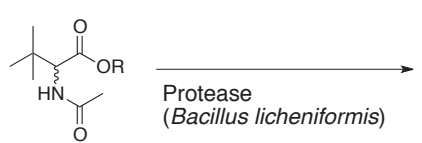

( \pm )- $N$-acetyl-tert-leucine chloroethyl ester

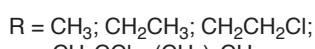

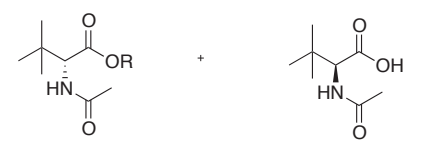

Heating with $10 \%$ aq. $\mathrm{HCl}$

$$
\underbrace{\mathrm{O}}_{\overline{\mathrm{N}} \mathrm{H}_{2}} \mathrm{OH}
$$

$\mathrm{D}$-tert-leucine
Scheme 1. Enzymatic hydrolysis of $( \pm)-N$-acetyl-tert-leucine chloroethyl ester into D-tert-leucine catalyzed by a protease from Bacillus licheniformis. ${ }^{[6]}$ The enzymatic reaction was carried out for $50 \mathrm{~h}$ at $35^{\circ} \mathrm{C}$ in a stirred $\mathrm{pH}$ stat (pH 8.0). The reaction solution consisted of $300 \mathrm{~mL}$ toluene in $800 \mathrm{~mL}$ phosphate buffer and $500 \mathrm{~mL}$ Alkalase solution. The isolated yield of D-tert-leucine was $43 \%(30.3 \mathrm{~g})$.

This protease showed a broad substrate tolerance and possessed an activity high enough for large-scale preparations. ${ }^{[9]}$ Consequently, the enzyme was also used to synthesize substituted phenylalanine derivatives, which are suitable synthons for proteasome inhibitors (Scheme 2).
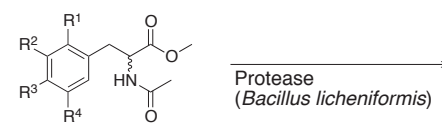

$\mathrm{R}^{1}=\mathrm{R}^{2}=\mathrm{R}^{3}=\mathrm{R}^{4}=\mathrm{H} ; \mathrm{CH}_{3} \mathrm{O} ; \mathrm{C}(\mathrm{O}) \mathrm{CH}_{3} ; \mathrm{Cl}$

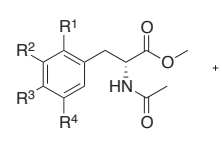

$\downarrow \mathrm{HCl}$ reflux

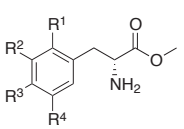

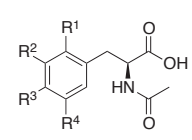

$\downarrow \mathrm{HCl}$ reflux

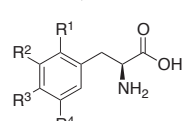

Scheme 2. Enzymatic synthesis of substituted phenylalanine derivatives catalyzed by a protease from Bacillus licheniformis. ${ }^{[9]}$ The enzymatic reaction was carried out for $7 \mathrm{~h}$ at room temperature in a stirred $\mathrm{pH}$ stat (pH 7.5). The reaction solution consisted of $430 \mathrm{~mL}$ toluene in 1,800 mL phosphate buffer and $0.3 \mathrm{~mL}$ Alkalase solution. The isolated yield of $(R)$ $\mathrm{N}$-acetyl amino acid ester was $49 \%(40 \mathrm{~g})$ and $(S)-N$-acetyl amino acid $25 \%$ (168 g).

Another example for the application of this protease is the preparation of an unnatural L-amino acid, which represents a building block for the $\beta$-secretase (BACE-1) inhibitors NB-544 and NB-533. These inhibitors can potentially be applied for the treatment of Alzheimer's disease (Scheme 3). ${ }^{[10]}$ In this (dynamic kinetic) resolution route, removal of the $N$-acetyl protecting group was achieved under catalysis of aminoacylase from Aspergillus sp. (Amano Acylase ${ }^{\circledR}$ ).

Next to proteases, various enzymes have been shown to perform unnatural reactions to produce non-proteinogenic amino ac-

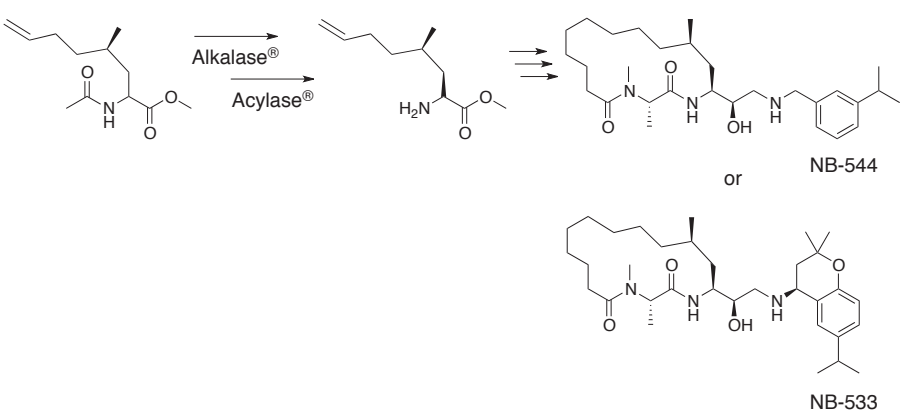

Scheme 3. Alkalase ${ }^{\circledR}$ and Acylase ${ }^{\circledR}$ catalyzed enzymatic synthesis of an unnatural L-amino acid serving as building blocks for the macrocyclic BACE1 inhibitors NB-544 and NB-533. ${ }^{[10]}$ The isolated yield was $5-11 \%$.

ids. However, there is still a need for novel enzymes to access a wider range of amino acids at a preparative scale. By means of protein engineering approaches, biocatalysts can be created yielding enantiomerically pure non-proteinogenic amino acids with high yield. [11,12] These engineered enzymes, also referred to as noncanonical amino acid synthases, enable the development of new precursors for pharmaceuticals and other high-value products. ${ }^{[13]}$

\subsection{Chiral Amines}

The enantioselective synthesis of chiral amines represents a biocatalysis success story promoted by various research groups. ${ }^{[14]}$ Chiral amines have a widespread application as building blocks in the pharmaceutical and fine chemical industry. Some recently developed biocatalysts are imine reductases, reductive aminases, amine dehydrogenases, ammonia lyases and $(S)$-selective transaminases expanding the product scope for secondary and tertiary amines. ${ }^{[14,15]}$

In his publications O. Ghisalba emphasized strongly the enantioselective amidohydrolases that catalyze the deacylation of compounds different from the typical substrate profile that are $N$-acetylated peptides, amino acids, and penicillin derivatives. 1-Phenylethylamine was chosen as model compound for screening whereas the main target compound was $(R)$-1-(3-cyanophenyl) ethylamine. (R)-1-(3-Cyanophenyl) ethylamine is a building block for a $\mathrm{GABA}_{\mathrm{B}}$ receptor antagonist potentially relevant for the treatment of Alzheimer's patients. The initially found $(S)$ specific amidohydrolase originated from Rhodococcus equi Ac6 and was inducible by the substrate $N$-acetyl-1-phenylethylamine (Scheme 4A). ${ }^{[16]}$ This enzyme is suitable for the production of various optically active amines. However, the cyano-substituted $(R)$-amines could not be obtained. Therefore, further habitat samples were screened using $N$-acetyl-1-phenylethylamine as sole carbon and energy source in order to identify new $(R)$-specific amidohydrolases. Arthobacter aurescens AcR5b, which was isolated from a haystack, deacetylates several $N$-acetyl1-phenylethylamine derivatives with $(R)$-preference (Scheme 4A). ${ }^{[17]}$ In contrast to the amidohydrolase from Rhodococcus equi, this enzyme is constitutively produced with a yield of up to $6,420 \mathrm{U} \mathrm{L}^{-1}$. Furthermore, Rhodococcus globerulus K1/1 was found to express another inducible amidohydrolase with high $(S)$-enantioselectivity (Scheme 4B). ${ }^{[18]}$ This enzyme has a different substrate range compared to that of Rhodococcus equi amidohydrolase and cleaves racemic $N$-acetyl-2-amino-1-phenyl-4pentene enantioselectively into $(S)$-2-amino-1-phenyl-4-pentene that is required as building block for anxiolytic and antidepressant ingredients.

These three enzymes with different specific selectivities and good operational stability are highly applicable for the preparative synthesis of enantiomerically pure amines. During the last 20 years, tens of thousands of new amidohydrolase encoding sequences were assigned and various amidohydrolase catalyzed 


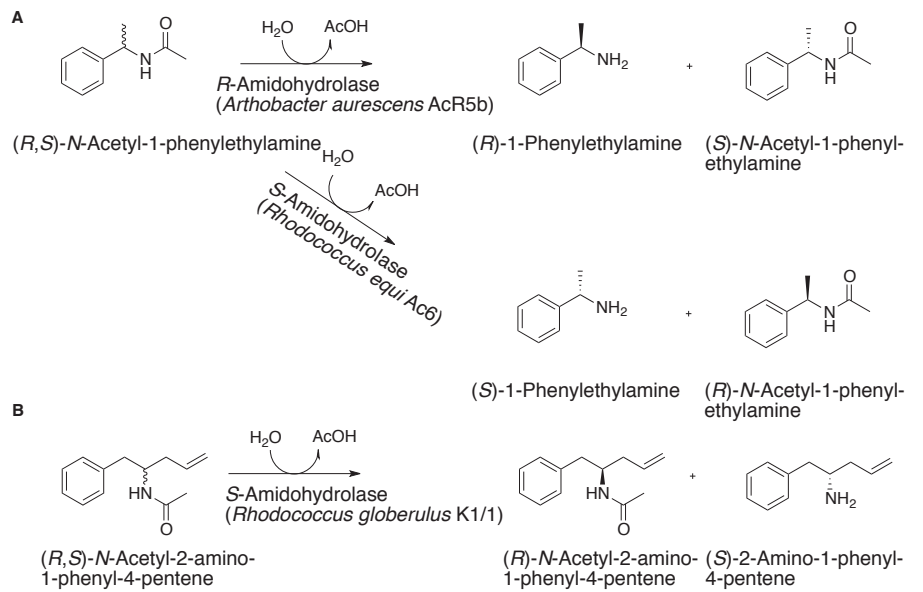

Scheme 4. Enantioselective deacetylation of racemic (A) N-acetyl-1phenylethylamine and (B) $N$-acetyl-2-amino-1-phenyl-4-pentene. ${ }^{[17,18]}$ The enzymatic reaction of $(R, S)$-acetyl-1-phenylethylamine was carried out for $22 \mathrm{~h}$ with $13 \mathrm{mM}$ substrate and $8.4 \mathrm{U} / \mathrm{mL}$ enzyme. The conversion was $50 \%$. The enzymatic reaction of $\mathrm{N}$-acetyl-2-amino-1-phenyl-4-pentene was carried out for $20 \mathrm{~h}$. An amount of $400 \mathrm{~g}$ was added to $50 \mathrm{~mL}$ buffer with $0.5 \mathrm{~g}$ cells. The conversion was $52 \%$ with a selectivity of 95 .

hydrolytic reactions reported. ${ }^{[19]}$ The probably best-known amidohydrolase is the $N$-carbamyl-D-amino acid amidohydrolase ( $N$-carbamoylase). $N$-carbamoylase is industrially used for nonproteinogenic $\mathrm{D}$-amino acid production and is also subject to research addressing the improvement of enzyme stability with regard to process conditions using directed evolution. ${ }^{[20]}$

\subsection{Enantiomerically Pure Inositol Phosphates}

Inositol phosphate and phospholipids are involved in physiological processes, e.g. as second messengers in regulatory processes. Inositol is produced chemically through acid hydrolysis of phytate and can also be synthesized by fermentation or enzymatically in large amounts. ${ }^{[21,22]}$ Derivatives of inositol phosphates are of great interest as tool for metabolic studies, as inhibitors or chiral building blocks. Therefore, chemo-enzymatic syntheses have been developed to gain access to inositol derivatives at a preparative scale. Eight chemical steps and lipasecatalyzed differentiation of the enantiotopic hydroxyl groups are necessary to synthesize D-myo-inositol-1-phosphate from D-myo-inositol via meso-4,6-di-O-benzyl-inositol by (Scheme 5A). ${ }^{[23]}$ In contrast to racemate resolution, this desymmetrization strategy theoretically allows full conversion to the desired enantiomer. Due to mild reaction conditions, migration of neither the acetyl group nor the phosphate group was observed. Another lipase from Candida antarctica was identified that acetylates regio- and enantioselectively, synthesizing exclusively L5-acetyl-2,6-di-O-benzyl-myo-inositol (Scheme 5B). ${ }^{[24]}$ These chemoenzymatic production routes have been extended and in the end twelve different inositol phosphates were synthesized at a preparative scale.[25]

These and other chiral and multifunctional molecules are now available as building blocks and research tools in drug discovery. However, the potential of biocatalysis or biosynthesis in organic synthesis is far from being fully exploited. For this reason, a group of life science companies in Switzerland, the Swiss Industrial Biocatalysis Consortium (SIBC), which is active in pharmaceuticals, flavor and fragrance, vitamin and fine chemicals business, describes some examples of the use of enzymes in industrial organic synthesis and discusses why enzymes are still the exception rather than the rule in this field. ${ }^{[26]}$ The goal of the SIBC is to push biotransformations to application in industry. The SIBC made some of the enzymes described here and make strains available to other partners of the consortium. ${ }^{[27]}$

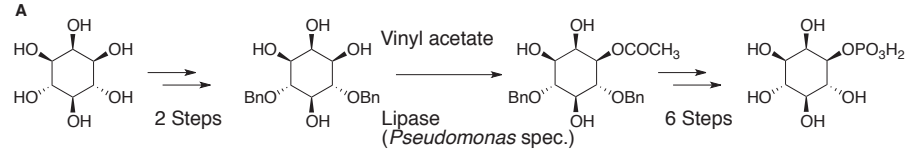

B
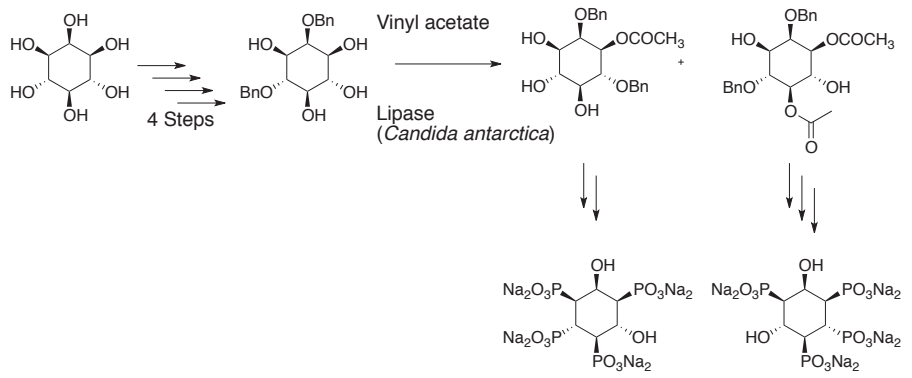

Scheme 5. Enzymatic key steps in the synthesis of $(A)$ D-myo-inositol1-phosphate (desymmetrization) and (B) D- and L-myo-inositol-1,3,4,5tetraphosphate (resolution). ${ }^{[23,24]}$ The isolated yield of D-myo-inositol1-phosphate was $58 \%$ with $3.67 \mathrm{~g}$ as the bis(cyclohexylammonium) salt. The enzyme reaction was carried out at room temperature with $5 \mathrm{~g}$ substrate in $100 \mathrm{~mL}$ vinyl acetate using $2.5 \mathrm{~g}$ lipase. The isolated yield of D- and L-myo-inositol-1,3,4,5-tetraphosphate was $40 \%$ with 2.9 and $3.31 \mathrm{~g}$ as the tetrapotassium salt, respectively. The enzymatic esterification was carried out for $92 \mathrm{~h}$ using $5.4 \mathrm{~g}$ substrate in $40 \mathrm{~mL}$ tetrahydrofuran, $100 \mathrm{~mL}$ vinyl acetate, and $2.5 \mathrm{~g}$ enzyme.

\section{Biocatalytic Synthesis of Drug Metabolites}

Drug metabolites are of interest to pharmaceutical companies for several reasons. On the one hand, they are used to characterize the metabolic pathway of a xenobiotic or drug candidate. On the other hand, investigations regarding their toxicity, biological activity and drug-drug-interactions are conducted. ${ }^{[28]}$ Furthermore, the generated metabolites can be used as reference substances in pharmacokinetic and -dynamic studies. ${ }^{[29]}$ Most drug metabolites are not commercially available and their chemical syntheses are often complex. ${ }^{[28]}$

Synthesis of human drug metabolites on a preparative scale can be achieved through either recombinant human enzymes or microbial biocatalysts. ${ }^{[30]}$ The application of enzymes for the discovery of new drug metabolites will be discussed. O. Ghisalba contributed especially in the identification and application of enzyme systems, which are of great use for preparative drug metabolite synthesis. The relevant enzyme classes are: cytochrome P450 monooxygenases (CYPs), xanthine oxidoreductases (XORs), flavin monooxygenases (FMOs), aldehyde oxidases (AOXs) and UDP-glucuronosyl transferases (UGTs).

\subsection{Recombinant Human P450 Monooxygenases (CYPs)}

CYPs are versatile biocatalysts for the introduction of hydroxyl groups at specific positions of drug molecules. These membrane-bound enzymes are mostly found in the liver and take part in phase I drug metabolism. ${ }^{[28]}$ Their spectrum of catalyzed reactions comprises hydroxylations, epoxidations, $N$ - and $O$-dealkylations and Baeyer-Villiger oxidations among others. ${ }^{[31]}$ It is highly beneficial to use recombinant human (rh) CYPs for preparative synthesis of drug metabolites, because of their high selectivity and specificity, even though the isolated yields are often small. The five major human CYP isoforms are CYP1A2, CYP2C9, CYP2C19, CYP2D6 and CYP3A4, which is the most active isoform on analytical level and for preparative applications. ${ }^{[28]}$ An example of a pharma research project, during which rhCYPs were used for the preparation of drug metabolites, is the generation of antagonists for metabotropic glutamate receptors (mGluR). These receptors modulate the excitability of the central nervous system (CNS). Subtype 5 (mGluR5) seems to act in pain and anxiety states, and alterations in neuronal excitability 
via the glutamatergic system have been identified as a cause of many CNS disorders. ${ }^{[32]}$ Therefore, it is important to find ways to modulate CNS excitability and mGluR5 antagonists can potentially be used to treat pain, Parkinson's disease (overactivity of the glutamatergic system) and drug abuse. ${ }^{[33]}$

The mGluR5 antagonist compound 1 is based on a piperidyl amide and shows anxiolytic-like effects. Different rhCYP isoforms, CYP1A1, 1A2 and 3A4, were produced in E. coli with co-expression of rhP450 reductase as co-factor regeneration system. The cultivation on a $25 \mathrm{~L}$ scale was conveniently performed in a $50 \mathrm{~L}$ wave-bioreactor. Whole-cells were used to catalyze the oxidation of compound 1 leading to various metabolites to simulate the degradation which had been observed during incubations with mammalian liver microsomes. The metabolites of compound 1 were generated for definite structure elucidation by NMR and biological activity testing. (Scheme 6). ${ }^{[34]}$

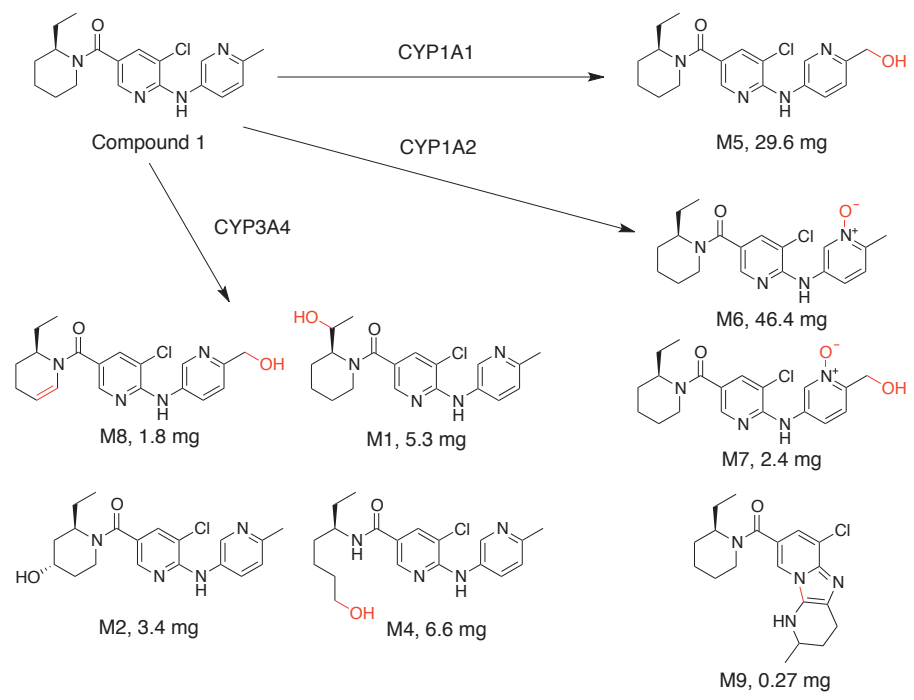

Scheme 6. Biotransformations of piperidyl-based compound 1 by different rhCYPs. ${ }^{[34]}$

\subsection{Bacterial P450 Monooxygenases (CYPs)}

Some bacterial CYPs are also able to catalyze the conversion of drugs into relevant compounds and are thus possible biocatalysts for drug metabolite biosynthesis. The advantages of bacterial CYPs in comparison with eukaryotic CYPs are the higher stability as well as higher catalytic activities and expression rates, when expressed heterologously. ${ }^{[35]}$ It has been shown that there is a correlation between microbial and mammalian oxidative drug metabolism to some extent. ${ }^{[36]}$ This can be seen in bacterial wildtype CYP102A7, which recognizes the same substrates as the human CYP2E1, e.g. chlorzoxanone, aniline and $p$-nitrophenol, and is 10 times faster than the human enzyme variant. ${ }^{[37]}$ CYP102A7 is a self-sufficient, bifunctional P450 monooxygenase (biCYP) which combines the heme domain and electron transfer domain in a single polypeptide chain. The enzyme was optimized by sitedirected mutagenesis to increase substrate conversion. In the end, mutant CYP102A7 A266G was able to reach a 44\% conversion of chlorzoxazone to its hydroxylated form compound 2 (Scheme 7) on a preparative scale in mg quantities. ${ }^{[38]}$

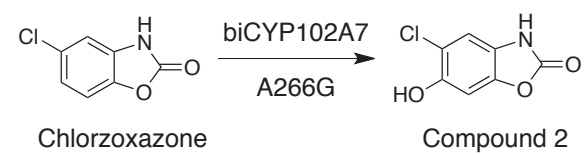

Scheme 7. Biotransformation of chlorzoxazone by a mutein of bifunctional CYP102A7. The reaction was carried out for $14 \mathrm{~h}$ at $30^{\circ} \mathrm{C}$ in a stirred $\mathrm{pH}$ stat. The isolated yield was $12 \% .^{[38]}$
In a recent study, new bacterial P450s were identified with a broad substrate scope regarding seven pharmaceuticals used as model substrates. These new P450s are promising for the hydroxylation of various compounds of pharmaceutical interest. ${ }^{[39]}$

\subsection{Flavin Monooxygenases (FMOs)}

Although a large number of drugs can be functionalized using FMOs, less attention has been paid to this enzyme class so far in comparison to CYPs. FMOs are membrane-bound and oxidize substrates containing a soft nucleophile, e.g. $\mathrm{N}$ or $\mathrm{S}$, while, as in CYP reactions, dehydrogenating NADPH and using the electrons to reduce one oxygen atom of $\mathrm{O}_{2}$ to $\mathrm{H}_{2} \mathrm{O}$. Of the six known human isoforms, hFMO3 is the most abundant in human liver cells. The preparation of the $N$-oxide of moclobemide using rhFMO3 in $E$. coli as a whole-cell biocatalyst represents the first multi$\mathrm{mg}$ scale synthesis applying this enzyme and yielded $65 \mathrm{mg}$ purified moclobemide- $N$-oxide (55\% yield, $>90 \%$ purity) after $24 \mathrm{~h}$ (Scheme 8A). Moclobemide is a reversible monoamine oxidase (MAO) inhibitor, which is primarily used to treat depression. This reaction is of interest because one of the major metabolic routes of moclobemide is the hFMO3 catalyzed $N$-oxidation. ${ }^{[40]}$ In another example, trifluoroperazine was shown to be oxidized selectively at the methylated nitrogen of the piperazine ring at a $50 \mathrm{mg}$ scale by rhFMO isoform $2 * 1$ expressed in $E$. coli (Scheme $8 \mathrm{~B})$. Chemical oxidation, however, led to a mixture of products devoid of the targeted human metabolite. ${ }^{[41]}$

A<smiles>O=C(NCCN1CCOCC1)c1ccc(Cl)cc1</smiles>

Moclobemide

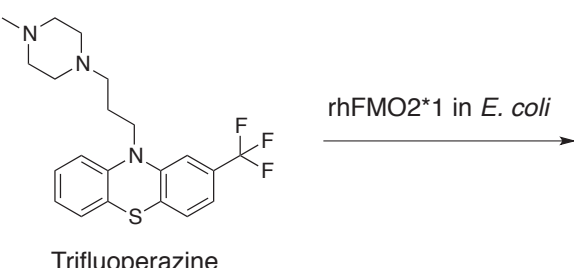

Trifluoperazine

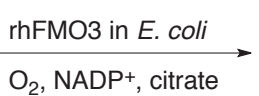

Moclobemide- $N$-oxide
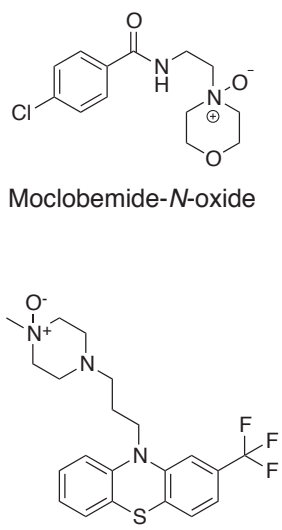

Trifluoperazine- $N^{1}$-oxide
Scheme 8. (A) Whole-cell catalyzed $\mathrm{N}$-oxidation of moclobemide with cofactor recycling. The reaction was carried out for 24 h. ${ }^{[40]}(B)$ Selective oxidation of Trifluoroperazine by rhFMO2*1 (E. coli whole-cell biocatalyst). ${ }^{[41]}$

\subsection{Xanthine Oxidoreductases (XORs)}

$\mathrm{XOR}$ is a soluble enzyme involved in the last steps of the purine metabolism and is a known activator of prodrugs with narrow substrate specificity. ${ }^{[42,43]}$ An example of its activator function is the biotransformation of uracil-based heterocycles such as 1,7-dihydro- $2 H$-pyrrolo[2,3- $d$ ] pyrimidin-2-one (Scheme 9A).

These molecules act as inhibitors of thymidine phosphorylase (TP), which is present in higher concentrations in tumor tissue compared to other tissues. TP promotes metastasis and angiogenesis while suppressing apoptosis, which makes its inhibition a promising approach for anti-cancer therapy. XOR is also present in elevated concentrations in tumor tissue, which gives rise to the opportunity of selective TP inhibition at the tumor site with XORactivated prodrugs. ${ }^{[44]}$

Another application of XOR is the preparative synthesis of drug metabolites, e.g. 4-quinazolinone, which is the human metabolite of the antimalarial drug quinazoline (Scheme 9B). The recombinant human xanthine oxidoreductase (rhXOR) was produced in E. coli whole-cells. The biotransformation using the 
whole $E$. coli cells as biocatalyst yielded $73 \mathrm{mg}$ of the product (63\% isolated yield, $95 \%$ purity). ${ }^{[45]}$

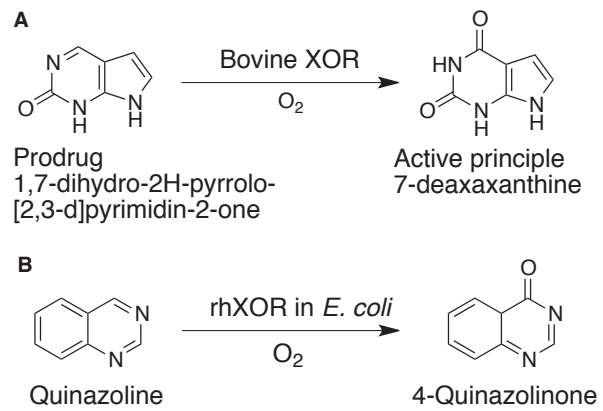

Scheme 9. (A) Biotransformation of prodrug 1,7-dihydro-2H-pyrrolo[2,3d]pyrimidin-2-one by bovine XOR to active drug 7-deaxaxanthine. ${ }^{[4]}$ (B) Biotransformation of quinazoline to 4-quinazolinone by rhXOR in E. coli whole-cells. ${ }^{[45]}$

\subsection{Aldehyde Oxidases (AOXs)}

AOXs are cytosolic enzymes, which show high activity in the liver. In humans, only one isoform, AOX1, exists. In contrast to CYPs, AOXs are independent of cofactors while using oxygen from water for oxidation and $\mathrm{O}_{2}$ as electron acceptor leading to the generation of $\mathrm{H}_{2} \mathrm{O}_{2} \cdot{ }^{[43]}$ Zaleplon is a sedative-hypnotic agent that is metabolized in different ways in humans and rats. While the 5-oxo-metabolite synthesis catalyzed by AOX prevailed in humans, the desethyl-metabolite catalyzed by CYP3A4 was predominantly detected in rats (Scheme 10). ${ }^{[46]}$

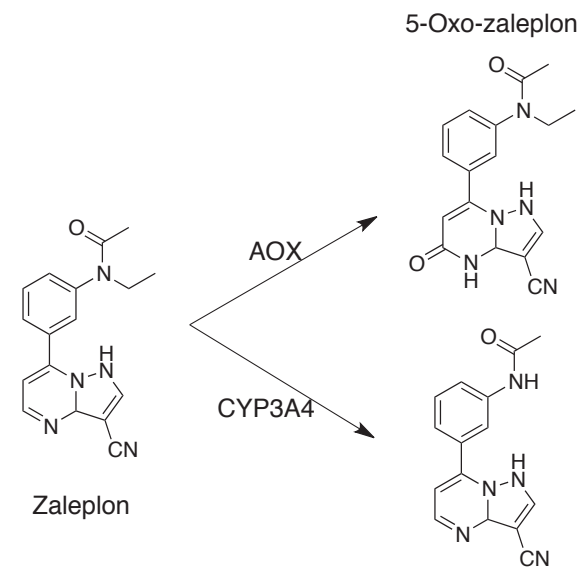

Desethylzaleplon

Scheme 10. Biotransformation of zaleplon with aldehyde oxidase (AOX) and cytochrome P450 CYP3A4 results in different transformation products. ${ }^{[46]}$

The high activity of the AOX in vivo can be challenging for drug development, because of the rapid degradation of drug candidates, which led to several clinical failures. ${ }^{[47]}$ Nevertheless, the catalytic activity of AOX can be exploited to convert a prodrug into its active form. An example is the prodrug famciclovir, used for the systemic treatment of varicella zoster virus. In the first step, famciclovir is hydrolyzed by rapid-first-pass metabolism in the intestines and liver to 6-deoxypenciclovir (Scheme 11). AOX then oxidizes 6-deoxypenciclovir to the active metabolite penciclovir, as Rashidi et al. have shown in vitro. ${ }^{[46,48]}$ The active metabolite penciclovir itself is used in other drugs for the local treatment of herpes simplex virus. ${ }^{[49]}$ Human AOX1 was expressed in E. coli in catalytically active form. ${ }^{[50,51]}$ The oxidation of famciclovir to diacetylpenciclovir under whole-cell biocatalysis on $200 \mathrm{mg}$ scale served as a model reaction to demonstrate the applicability of this biocatalyst for preparative metabolite synthesis. ${ }^{[51]}$

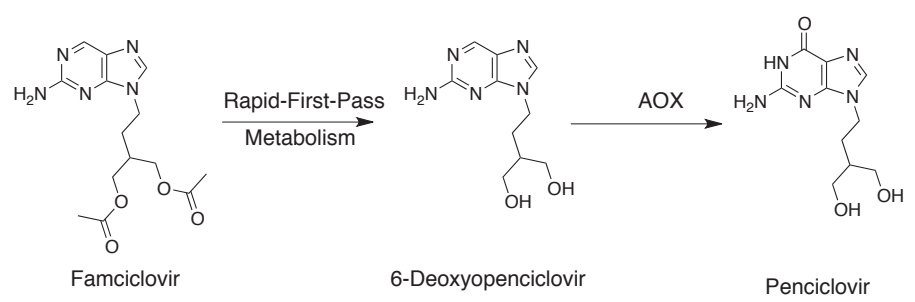

Scheme 11. Biotransformation of prodrug famciclovir to its active metabolite penciclovir by rapid-first-pass metabolism and aldehyde oxidase $(\mathrm{AOX}){ }^{[46]}$

\subsection{UDP-glucuronosyltransferases (UGTs)}

UDP-glucuronosyltransferases (UGTs) are important enzymes of the phase II metabolism of xenobiotics. They are responsible for the glucuronidation reaction, which transforms for example potentially harmful lipophilic into hydrophilic compounds. ${ }^{[52]}$ As biocatalysts, UGTs are useful for the preparative synthesis of drug metabolites. Furthermore, glucuronides of pharmacologically active compounds are discussed as potential prodrugs, from which the effective principle is released in the target tissue in order to reduce overall exposition and hence, toxicity. ${ }^{[53]}$ At ScheringPlough (New Jersey, USA), Zaks and Dodds used commercially available UGT from bovine liver and UDP-glucuronic acid as the co-substrate to prepare with high yield $200 \mathrm{mg}$ of the phenolic glucuronide of Sch 58235, a novel inhibitor of cholesterol absorption (Scheme 12). ${ }^{[54]}$

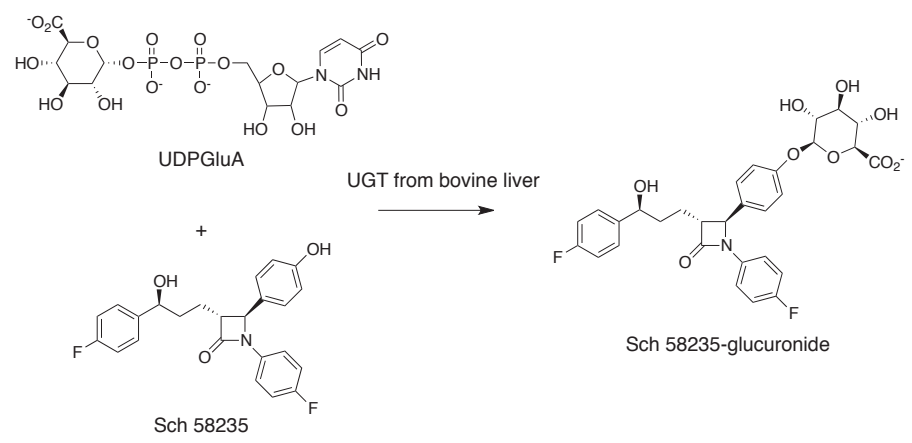

Scheme 12. Biocatalytic glucuronidation of Sch 58235. ${ }^{[54]}$

The synthesis of stable isotope-labeled Sch $58235-{ }^{13} \mathrm{C}_{6}-$ glucuronide was performed under the catalysis of eight commercially available enzymes. In addition to the UGT effecting glucuronidation, seven enzymes served for the in situ generation of UDP- ${ }^{13} \mathrm{C}_{6}$-glucuronic acid from ${ }^{13} \mathrm{C}_{6}$-glucose (Scheme 13). ${ }^{[54]}$

Besides commercially available enzymes, also easily obtainable liver preparations can be used efficiently for preparative glucuronide conjugation. Pfaar et al. at Novartis (Basel, Switzerland) applied a liver preparation from guinea-pig for the glucuronidation of two compounds. One of them was formoterol, a bronchodilating drug for the treatment of asthma and COPD. ${ }^{[53]}$ The biotransformations were conducted continuously in an enzyme membrane reactor. The substrate solution containing the aglycon and UDP-glucuronic acid was pumped through the reactor, in which the liver preparation containing the catalytically active UGT was retained with an ultrafiltration membrane. 50-65\% conversion of formoterol was achieved and between 76 and $90 \%$ of 6-(2-[(1-methylethyl)amino]propyl)pyridin-3-ol, the second test substrate (Scheme 14). 


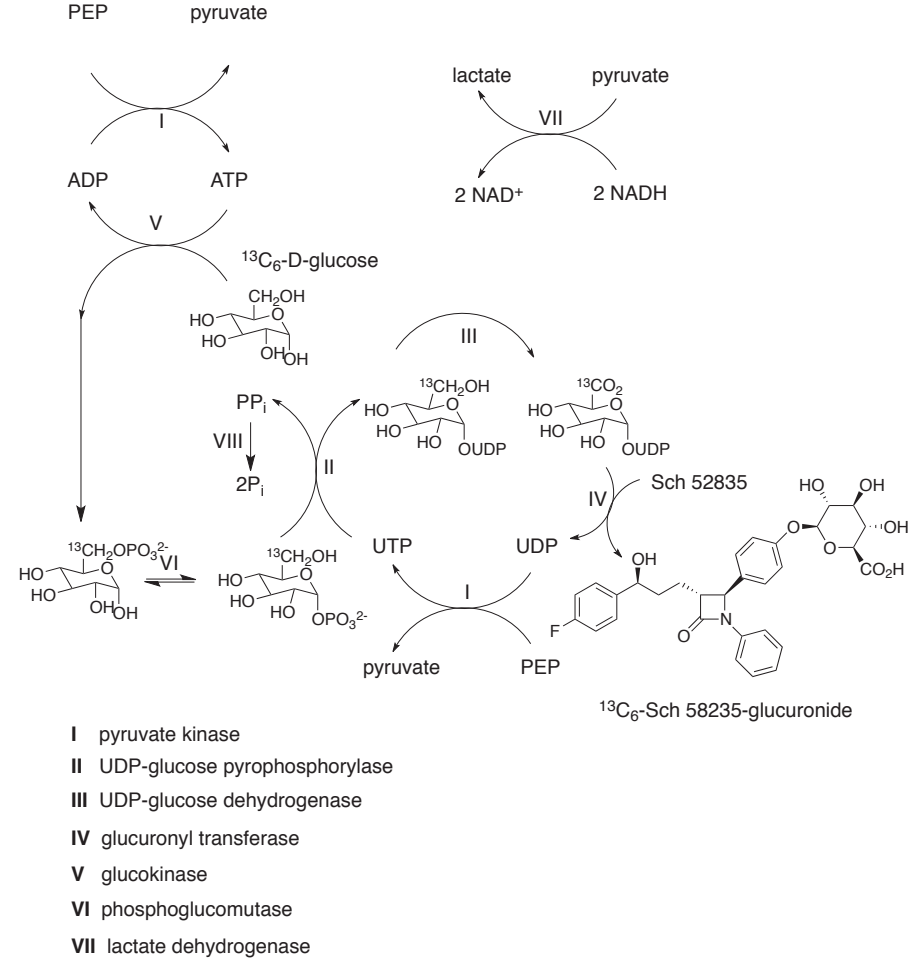

Scheme 13. Enzymatic synthesis of Sch $58235-{ }^{13} \mathrm{C}_{6}$-glucuronide under the in situ generation of UDP- ${ }^{13} \mathrm{C}_{6}$-glucuronic acid. PEP $=$ phosphoenol pyruvate. ${ }^{[54]}$

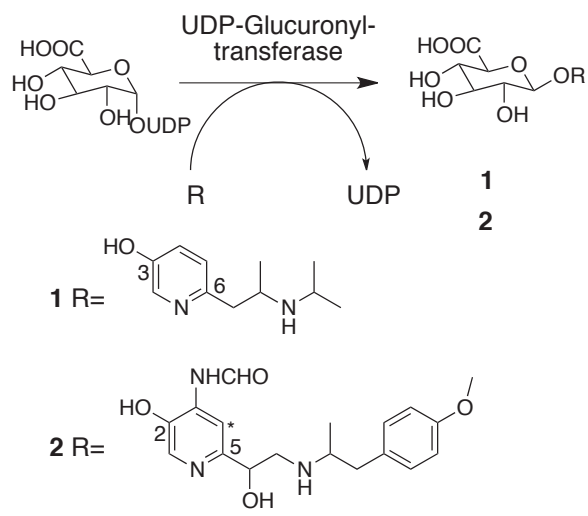

Scheme 14. Continuous enzymatic glucuronidation of formoterol and 6-(2-[(1-methylethyl)amino]propyl)pyridin-3-ol in an enzyme membrane reactor. $^{[53]}$

The 250-300 $\mathrm{mL}$ preparative scale glucuronidation of mycophenolic acid (MPA) is another example, where a selected liver preparation served as efficient biocatalyst. MPA is an immunosuppressive drug, which is metabolized in humans by UGT1A10 to acyl- and $O$-glucuronide (Scheme 15 ). While the acylglucuronide is biologically active and only produced in traces, the inactive $O$-glucuronide is the major metabolite with an acyl- to $O$-glucuronide ratio of 1:80 in humans. The acylglucuronide was required in multi-mg quantities for pharmacological studies in vitro. Therefore, a screening of liver preparations from other vertebrate species was conducted to increase the acyl-to- $O$-glucuronide ratio. Horse liver preparation S9 yielded the best results with a $1: 1$ ratio. ${ }^{[55]}$ Chemical syntheses did not lead to the desired goal, especially since drug glucuronides are often unstable and chemical production methods are harsh in comparison to the mild reaction conditions during enzymatic biosynthesis. [56]

All in all, the relevance of biocatalysts for the discovery and preparative synthesis of drug metabolites has been demonstrated.

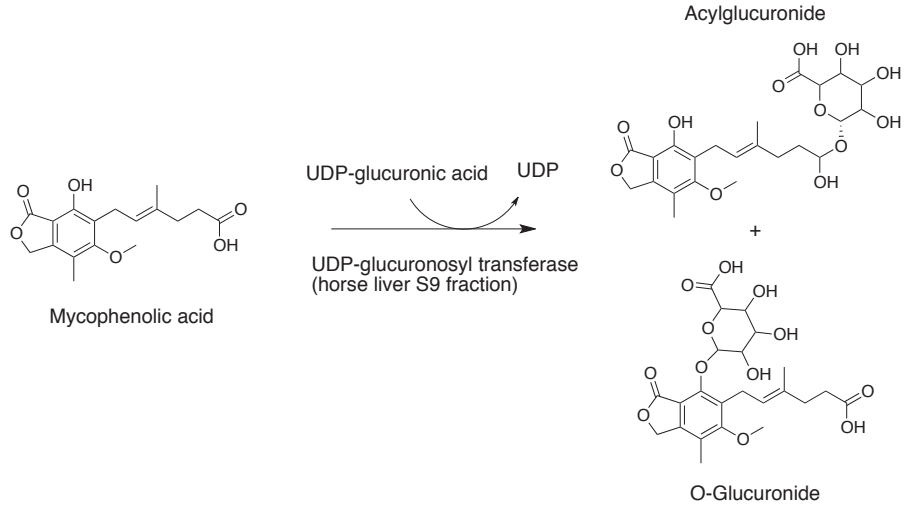

Scheme 15. Enzymatic synthesis of acylglucuronide from mycophenolic acid. ${ }^{[55]}$

The biosynthetically generated drug metabolites are valuable compounds for pharmacokinetic and-dynamic studies.

\section{Late-stage Functionalization}

Biocatalytic modifications of natural products (NPs) take place in all living organisms and cause changes in the molecules' physicochemical properties such as their solubility, lipophilicity, and pKs. ${ }^{[57]}$ Such modifications can be used for the improvement of, for example, the stability or bioavailability of drugs. In this section, four types of biocatalytic modifications will be discussed: oxidations, $O$-methylations, phosphorylations, and halogenations.

\subsection{Biocatalytic Modification of NPs by Oxidation Reactions}

Many forms of cancer are caused by an abnormal activity of the hedgehog pathway. Thus, inhibitors of hedgehog signaling are promising novel anticancer drugs. The steroidal alkaloid cyclopamine is a powerful inhibitor of the hedgehog pathway. However, cyclopamine displays low oral bioavailability, suboptimal pharmacokinetics and low metabolic stability, especially in acidic environment. This fueled research regarding derivatives with similar potency as cyclopamine, but better physicochemical properties. One of the resulting derivatives is the semisynthetic derivative IPI-926. ${ }^{58,59]}$ Furthermore, modifications can be introduced into cyclopamine through biotransformations. The Bioreactions group of Novartis, Basel, used three different bacterial strains, Mucor cirinelloides, Brevibacterium healii, and Mortiella ramanniana, for the biotransformation of cyclopamine to generate metabolites for the determination of structure-activity relationships within an early medicinal chemistry project (Scheme 16). Especially the compound obtained with $B$. healii showed a lowered $\mathrm{IC}_{50}$ value and is therefore a stronger inhibitor of the hedgehog pathway. ${ }^{[60]}$

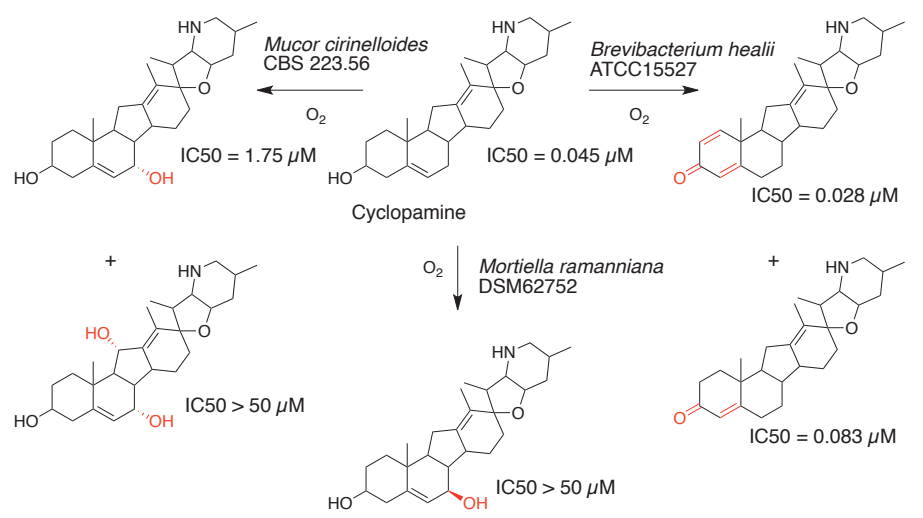

Scheme 16. Derivatives of cyclopamine and their inhibitory concentrations. ${ }^{[60]}$ 
Another NP, cladosporin, was subjected to biotransformations on a preparative scale to yield a set of new cladosporin derivatives: $38.1 \mathrm{mg}$ of compound 2 and $8.7 \mathrm{mg}$ of compound 3 (Scheme 17). Cladosporin is of interest because of its antiplasmodial activity, which is caused by inhibition of lysyl-tRNA-synthetase. The resulting hydroxylated products showed reduced activity in comparison to the parent compound, but were useful for the determination of structure-activity relationships, since the parent compounds were hydroxylated at five different carbon centers. The results indicated that the introduction of a hydroxyl group at $\mathrm{C} 4$ or $\mathrm{C} 4$ ' improves bioavailability.[61]

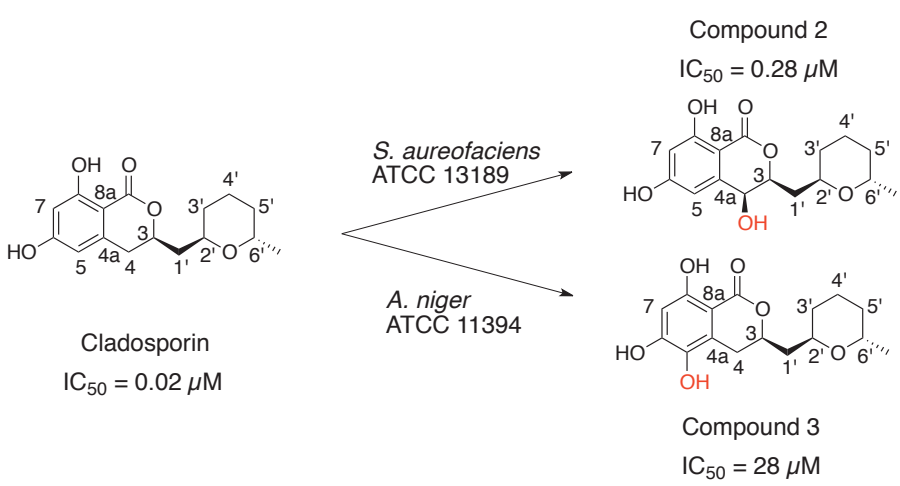

Scheme 17. Biotransformation of antiplasmodial compound cladosporin by Streptomyces aureofaciens ATCC 13189 and Aspergillus niger ATCC 11394 to hydroxylated products. ${ }^{[61]}$

\subsection{Biocatalytic Modification of NPs by O-Methylation Reactions}

Methylations of NPs possess a high biological impact. The methylation of hormones, nucleotides, and proteins is responsible for the induction of growth and regulatory processes. The addition of a methyl group changes the solubility and lipophilicity of a molecule and can affect its intracellular localization and interactions with target proteins. The transferred methyl groups usually originate from $S$-adenosyl-L-methionine (SAM), nature's most abundant methyl donor. SAM is unstable in aqueous solutions and slowly epimerizes to its inactive $(R, S)$-form. It is therefore an expensive cofactor. SAM can be provided by the cell itself in whole-cell biotransformations or regenerated in vitro by a cyclic regeneration system.[62]

Using whole-cell biocatalysis, the odor and the pharmacological activity of compounds can be influenced by changing the methylation pattern. An example is the $O$-methylation of aromadendrin, a flavonolol from the Siberian pine (Scheme 18). The natural molecule is not biologically active but exhibits anticancer properties when methylated through an $O$-methyltransferase (OMT). ${ }^{[57]}$

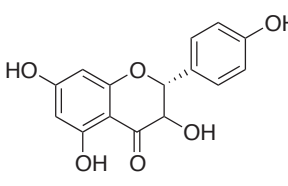

Aromadendrin

No anticancer activity

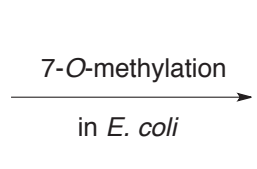
in E. coli

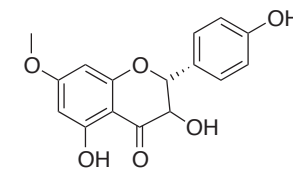

7-O-Methyl aromadendrin

Anticancer activity
Scheme 18. Methylation of aromadendrin in $E$. coli leads to anticancer active 7-O-methyl aromadendrin. ${ }^{[63]}$

OMTs accept many different substrates, possess high specificity and regioselectivity and form products in high yields. Another example of their successful application is the biotransformation of cheap naringenin extracted from citrus fruit peel by heterologous expression of an OMT gene from Glycine max, the soybean. It leads to the rare phytochemical ponciretin, which is known for its anti-inflammatory properties (Scheme 19).[57,64]

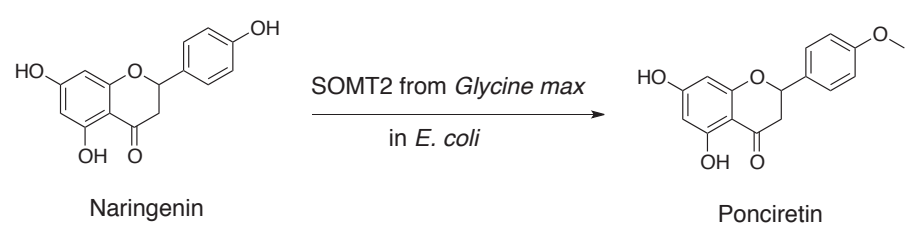

Scheme 19. Biotransformation of naringenin to ponciretin by O-methylation through heterologously expressed SOMT2 in E. coli. ${ }^{[57]}$

\subsection{Biocatalytic Modification of NPs by Phosphorylation Reactions}

Cellular life depends on phosphate esters, which can be found in relatively small molecules such as cofactors, but also in larger molecules such as phosphoproteins, phospholipids and nucleic acids. With common phosphate donors, such as adenosine triphosphate (ATP) and polyphosphate, phosphorylated metabolites, which are important for the elucidation of biochemical pathways, are generated.[65]

Phosphorylation reactions provide activated molecules, e.g. activated sugar moieties, which are necessary for the biosynthetic production of carbohydrates and are also of use for the glycosylation of NPs, which often possess biological activities. ${ }^{[66]}$ One mode of activation is the addition of guanosine-5'-diphosphate (GDP) by a combination of three enzymes (Scheme 20). The $N$-acetylhexosamine kinase from Bifidobacterium infantis (NahK_15697) catalyzes the phosphorylation of sugars at position C1. Then, the GDP-mannose pyrophosphorylase from Pyrococcus furiosus (PFManC) catalyzes the formation of the GDP-sugar and release of pyrophosphate. This is hydrolyzed to inorganic phosphate by endogenous E. coli's inorganic phosphatase to drive the reaction equilibrium towards the GDP-sugar by removing the pyrophosphate byproduct. NahK_15697 is a promiscuous enzyme. It is therefore possible to produce different GDP-sugars and their derivatives with this in vitro enzyme cascade.[67]

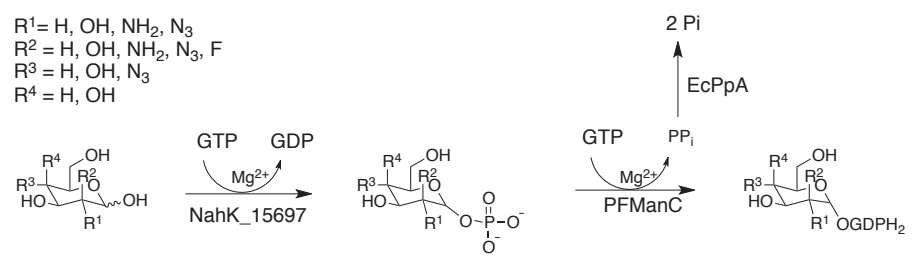

Scheme 20. Three-enzyme, one-pot in vitro reaction for the activation of sugars with GDP. NahK_15697 (N-acetylhexosamine kinase) from Bifidobacterium infantis, PFManC (GDP-mannose pyrophosphorylase) from Pyrococcus furiosus and EcPpA (inorganic phosphatase) from $E$. coli ${ }^{[67]}$

\subsection{Biocatalytic Modification of NPs by Halogenation Reactions}

The introduction of a halogen atom changes the properties of a molecule and may influence its metabolization. In a recent study, a natural non-heme iron halogenase with a narrow substrate scope of indole alkaloid-type substrates was evolved through protein engineering to accept a fragment of the pharmaceutically relevant compound martinelline (Scheme 21). The biotransformation of the non-natural substrate with the engineered WelO5* variants, which were overexpressed in E. coli, was carried out in deep well plates under addition of chlorine ions. The late-stage halogenation of non-natural substrates will yield value-added chemicals. ${ }^{[68]}$ 


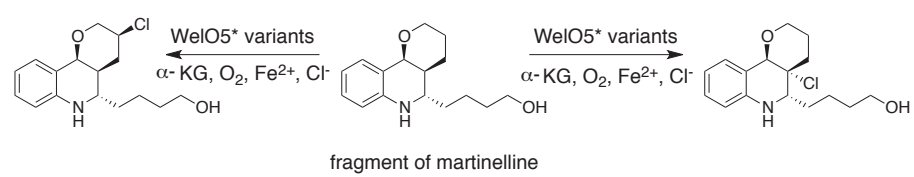

Scheme 21. Chlorination of a fragment of martinelline by WelO5* variants of non-heme iron halogenases overexpressed in E. coli BL21 (DE3) in deep well plates. ${ }^{[68]}$

In summary, the importance of biocatalytic modifications of natural products, especially regarding pharmacological activities, has been shown. The probably most prominent example is the anticancer activity of 7-O-methyl aromadendrin achieved through the $O$-methylation of aromadendrin by OMT.

\section{Outlook}

Oreste Ghisalba recognized the potential of enzymes decades ago and thanks to his visionary efforts and pioneering work in biocatalysis, paved the way to the successful adoption of enzymes in drug discovery, which later spread into drug development. With increasing access to novel enzymes as a result of rich and vibrant discovery and engineering efforts and a collaborative research community, this technology can be applied routinely on commercial manufacturing scale. A second fundamental advantage of biocatalysis is the ability to support green and sustainable manufacturing of drugs at Novartis ${ }^{[69,70]}$ and elsewhere. Advances in the development of retrosynthetic software and machine learning ensure the application of biocatalysis in the future. Predictive models support enzyme engineering, for example by determination of the best combination of mutations to enhance selectivity towards certain educts, while the screening of large molecule libraries with computational models allows the quick and effective identification of new drug molecules. ${ }^{[71,72]}$ Certainly, biocatalysis is an exciting area to be involved in and to experience the massive advances in real time.

\section{Acknowledgements}

Support of past and current members of the Novartis Bioreactions group in the presented projects is gratefully acknowledged.

Received: February 25, 2020

[1] P. D. de María, G. de Gonzalo, A. R. Alcántara, Catalysts 2019, 9, DOI 10.3390/catal9100802.

[2] S. P. Hanlon, H. Iding, E. Kupfer, B. Wirz, R. M. Howard, V. A. Martin, J. Wong, M. Kittelmann, K. Laumen, S. Lütz, M. Truppo, in 'Practical Methods for Biocatalysis and Biotransformations 2', Eds. J. Whittall, P. W. Sutton, Wiley-VCH, Weinheim, 2012.

[3] A. Vogel, in 'Industrial Enzyme Applications', 1. Edition ed., Eds. A. Vogel, O. May, Wiley-VCH Verlag GmbH \& Co. KGaA, Weinheim, 2019, pp. 25, DOI: 10.1002/9783527813780.ch1_2.

[4] J. P. Adams, M. J. B. Brown, A. Diaz-Rodriguez, R. C. Lloyd, G. D. Roiban, Adv. Synth. Catal. 2019, 361, 2421, DOI: 10.1002/adsc.201900424.

[5] R. J. Fox, S. C. Davis, E. C. Mundorff, L. M. Newman, V. Gavrilovic, S. K. Ma, L. M. Chung, C. Ching, S. Tam, S. Muley, J. Grate, J. Gruber, J. C. Whitman, R. A. Sheldon, G. W. Huisman, Nat. Biotechnol. 2007, 25, 338, DOI: $10.1038 /$ nbt1286.

[6] K. Laumen, O. Ghisalba, K. Auer, Biosci. Biotechnol. Biochem. 2001, 65 , 1977, DOI: $10.1271 / \mathrm{bbb} .65 .1977$

[7] U. Kragl, W. Kruse, W. Hummel, C. Wandrey, Biotechnol. Bioeng. 1996 52, 309, DOI: 10.1002/(SICI)1097-0290(19961020)52:2<309::AIDBIT11>3.0.CO;2-E.

[8] K. Drauz, M. Schwarm, Chem. Eur. J. 1995, 1, 538, DOI: 10.1002/ chem.19950010807.

[9] K. Laumen, O. Ghisalba, Eng. Life Sci. 2006, 6, 193, DOI: 10.1002/ elsc. 200620905.

[10] R. Machauer, K. Laumen, S. Veenstra, J. M. Rondeau, M. TintelnotBlomley, C. Betschart, A. L. Jaton, S. Desrayaud, M. Staufenbiel, S. Rabe, P. Paganetti, U. Neumann, Bioorganic Med. Chem. Lett. 2009, 19, 1366, DOI: $10.1016 /$ j.bmcl.2009.01.055.

[11] C. Boville, S. Brinkmann, A. Buller, D. Romney, C. Prier, P. Koch, R. Scheele, US 2018/0327793 A1, 2018.
[12] A. Buller, S. Brinkmann-Chen, M. Herger, D. Romney, M. Calles, P. Roye, US 2016/0298152 A1, 2016.

[13] P. J. Almhjell, C. E. Boville, F. H. Arnold, Chem. Soc. Rev. 2018, 47, 8980, DOI: $10.1039 / \mathrm{c} 8 \mathrm{cs} 00665 \mathrm{~b}$.

[14] R. A. Sheldon, D. Brady, ChemSusChem 2019, 12, 2859, DOI: 10.1002/ cssc. 201900351

[15] K. Rosenthal, S. Lütz, Curr. Opin. Green Sustain. Chem. 2018, 11, 58, DOI: 10.1016/j.cogsc.2018.03.015.

[16] A. Brunella, M. Graf, M. Kittelmann, K. Laumen, O. Ghisalba, Appl. Microbiol. Biotechnol. 1997, 47, 515, DOI: DOI 10.1007/ s002530050965.

[17] M. Graf, A. Brunella, M. Kittelmann, K. Laumen, O. Ghisalba, Appl. Microbiol. Biotechnol. 1997, 47, 650, DOI: 10.1007/s002530050990.

[18] P. Wahl, P. Walser-Volken, K. Laumen, M. Kittelmann, O. Ghisalba, Appl. Microbiol. Biotechnol. 1999, 53, 12, DOI: DOI 10.1007/s002530051607.

[19] E. Sugrue, N. J. Fraser, D. H. Hopkins, P. D. Carr, J. L. Khurana, J. G. Oakeshott, C. Scott, C. J. Jackson, Appl. Environ. Microbiol. 2015, 81, 2612, DOI: 10.1128/AEM.04016-14.

[20] K. H. Oh, S. H. Nam, H. S. Kim, Protein Eng. 2002, 15, 689, DOI: 10.1093/ protein/15.8.689.

[21] C. You, T. Shi, Y. Li, P. Han, X. Zhou, Y. H. P. Zhang, Biotechnol. Bioeng. 2017, 114, 1855, DOI: 10.1002/bit.26314.

[22] I. Brockman, K. Prather, Metab. Eng. 2015, 28, 104, DOI: 10.1038/nbt.3301. Mammalian.

[23] K. Laumen, O. Ghisalba, Biosci. Biotechnol. Biochem. 1994, 58, 2046, DOI: 10.1271/bbb.58.2046.

[24] K. Laumen, O. Ghisalba, Biosci. Biotechnol. Biochem. 1999, 63, 1374, DOI: 10.1271/Bbb.63.1374.

[25] H. van der Goot, 'Trends in Drug Research II', Elsevier Science, 1998

[26] H. P. Meyer, E. Eichhorn, S. Hanlon, S. Lütz, M. Schurmann, R. Wohlgemuth, R. Coppolecchia, Catal. Sci. Technol. 2013, 3, 3371, DOI: 10.1039/c2cy20350b.

[27] B. Wirz, M. Kittelmann, H. P. Meyer, R. Wohlgemuth, Chimia 2010, 64, 780, DOI: $10.2533 /$ chimia.2010.780.

[28] K. Schroer, M. Kittelmann, S. Lütz, Biotechnol. Bioeng. 2010, 106, 699, DOI: $10.1002 /$ bit. 22775 .

[29] M. Kittelmann, A. Kuhn, A. Riepp, J. Kühnöl, A. Fredenhagen, L. Oberer, O. Ghisalba, S. Lütz, in 'Practical Methods for Biocatalysis and Biotransformations 2', 2012, p. 146.

[30] O. Ghisalba, M. Kittelmann, in 'Modern Biooxidation', 2007, p. 214.

[31] A. Chefson, K. Auclair, Mol. Biosyst. 2006, 2, 462, DOI: 10.1039/ b607001a.

[32] D. D. Schoepp, J. Pharmacol. Exp. Ther. 2001, 299, 12.

[33] W. Danysz, C. G. Parsons, I. Bresink, G. Quack, Drug News Perspect. 1995, $8,261$.

[34] M. Kittelmann, A. Kuhn, A. Riepp, J. Kühnöl, A. Fredenhagen, L. Oberer, O. Ghisalba, S. Lütz, in 'Practical Methods for Biocatalysis and Biotransformations 2', 2012, pp. 138.

[35] V. B. Urlacher, S. G. Bell, L.-L. Wong, in 'Modern Biooxidation', 2007, pp. 99.

[36] O. Ghisalba, M. Kittelmann, in 'Modern Biooxidation', 2007, p. 221.

[37] G. Di Nardo, A. Fantuzzi, A. Sideri, P. Panicco, C. Sassone, C. Giunta, G. Gilardi, J. Biol. Inorg. Chem. 2007, 12, 313, DOI: 10.1007/s00775-0060188-4.

[38] R. Weis, M. Winkler, M. Schittmayer, S. Kambourakis, M. Vink, J. David Rozzell, A. Glieder, Adv. Synth. Catal. 2009, 351, 2140, DOI: 10.1002/ adsc. 200900190.

[39] L. M. Schmitz, J. Schäper, K. Rosenthal, S. Lütz, ChemCatChem Catal. 2019, 11, DOI: $10.1002 /$ cctc. 201901273 .

[40] S. P. Hanlon, M. Kittelmann, M. Winkler, in 'Practical Methods for Biocatalysis and Biotransformations 3', 2016, pp. 135.

[41] M. Geier, T. Bachler, S. P. Hanlon, F. K. Eggimann, M. Kittelmann, H. Weber, S. Lütz, B. Wirz, M. Winkler, Microb. Cell Fact. 2015, 14, 1, DOI: 10.1186/s12934-015-0262-0.

[42] C. A. Pritsos, Chem. Biol. Interact. 2000, 129, 195, DOI: 10.1016/S00092797(00)00203-9.

[43] L. Di, Expert Opin. Drug Metab. Toxicol. 2014, 10, 379, DOI: 10.1517/17425255.2014.876006.

[44] P. Reigan, A. Gbaj, E. Chinje, I. J. Stratford, K. T. Douglas, S. Freeman, Bioorganic Med. Chem. Lett. 2004, 14, 5247, DOI: 10.1016/j. bmcl.2004.08.036.

[45] M. Ferreira Antunes, F. K. Eggimann, M. Kittelmann, S. Lütz, S. P. Hanlon, B. Wirz, T. Bachler, M. Winkler, J. Biotechnol. 2016, 235, 3, DOI: 10.1016/j. jbiotec.2016.03.045.

[46] S. Sanoh, Y. Tayama, K. Sugihara, S. Kitamura, S. Ohta, Drug Metab. Pharmacokinet. 2015, 30, 52, DOI: 10.1016/j.dmpk.2014.10.009.

[47] J. M. Hutzler, R. S. Obach, D. Dalvie, M. A. Zientek, Expert Opin. Drug Metab. Toxicol. 2013, 9, 153, DOI: 10.1517/17425255.2013.738668.

[48] M. R. Rashidi, J. A. Smith, S. E. Clarke, C. Beedham, Drug Metab. Dispos. 1997, 25, 805 .

[49] M. H. Schmid-Wendtner, H. C. Korting, Skin Pharmacol. Physiol. 2004, 17, 214, DOI: $10.1159 / 000080214$ 
[50] J. F. Alfaro, C. A. Joswig-Jones, W. Ouyang, J. Nichols, G. J. Crouch, J. P. Jones, Drug Metab. Dispos. 2009, 37, 2393, DOI: 10.1124/ dmd.109.029520.

[51] D. Rodrigues, M. Kittelmann, F. Eggimann, T. Bachler, S. Abad, A. Camattari, A. Glieder, M. Winkler, S. Lütz, ChemCatChem 2014, 6, 1028, DOI: $10.1002 /$ cctc. 201301094

[52] M. Ouzzine, S. Gulberti, N. Ramalanjaona, J. Magdalou, S. FournelGigleux, Front. Cell. Neurosci. 2014, 8, 1, DOI: 10.3389/fncel.2014.00349.

[53] U. Pfaar, D. Gygax, W. Gertsch, T. Winkler, O. Ghisalba, Chimia 1999, 53, 590.

[54] A. Zaks, D. R. Dodds, Appl. Biochem. Biotechnol. - Part A Enzym. Eng. Biotechnol. 1998, 73, 205, DOI: 10.1007/BF02785656.

[55] M. Kittelmann, U. Rheinegger, A. Espigat, L. Oberer, R. Aichholz, E. Francotte, O. Ghisalba, Adv. Synth. Catal. 2003, 345, 825, DOI: 10.1002/ adsc. 200303044.

[56] M. Kittelmann, L. Oberer, R. Aichholz, O. Ghisalba, in 'Practical Methods for Biocatalysis and Biotransformations', 2010, pp. 251.

[57] L. Wessjohann, A.-K. Bauer, M. Dippe, J. Ley, T. Geißler, in 'Applied Biocatalysis', 2016, pp. 123.

[58] P. Heretsch, L. Tzagkaroulaki, A. Giannis, Angew. Chem. Int. Ed. 2010, 49, 3418, DOI: 10.1002/anie.200906967.

[59] Q. X. Liu, X. Yuan, J. Ye, R. C. Yue, Y. H. Shen, L. Shan, H. L. Li, W. D. Zhang, Phytochem. Lett. 2015, 12, 203, DOI: 10.1016/j.phytol.2015.04.006.

[60] S. Bleif, A. Riepp, M. Mösinger, G. Stutz, J. Kühnöl, M. Kittelmann, S. Roggo, K. Schroer, S. Lütz, Unpubl. results.

[61] A. Fredenhagen, K. Schroer, H. Schröder, D. Hoepfner, M. Ligibel, L. Porchet Zemp, C. Radoch, E. Freund, A. Meishammer, ChemBioChem 2019, 20, 650, DOI: $10.1002 /$ cbic. 201800588 .

[62] S. Mordhorst, J. Siegrist, M. Müller, M. Richter, J. N. Andexer, Angew. Chem. Int. Ed. 2017, 56, 4037, DOI: 10.1002/anie.201611038.

[63] S. Malla, M. A. G. Koffas, R. J. Kazlauskas, B. G. Kim, Appl. Environ Microbiol. 2012, 78, 684, DOI: 10.1128/AEM.06274-11.
[64] G. D. Kang, D. H. Kim, Int. Immunopharmacol. 2017, 43, 179, DOI: 10.1016/j.intimp.2016.12.021.

[65] D. Gauss, B. Schönenberger, S. Molla, Getachew, B. M. Kinfu, J. Chow, A. Liese, W. R. Streit, R. Wohlgemuth, in 'Applied Biocatalysis', 2016, pp. 147.

[66] C. J. Thibodeaux, C. E. Melançon, H. W. Liu, Angew. Chem. Int. Ed. 2008 47, 9814, DOI: 10.1002/anie.200801204.

[67] L. Li, Y. Liu, Y. Wan, Y. Li, X. Chen, W. Zhao, P. G. Wang, Org. Lett. 2013, 15, 5528, DOI: $10.1021 / \mathrm{ol} 402585 \mathrm{c}$.

[68] T. Hayashi, M. Ligibel, E. Sager, M. Voss, J. Hunziker, K. Schroer, R. Snajdrova, R. Buller, Angew. Chem. Int. Ed. 2019, 58, 18535, DOI: 10.1002/ anie. 201907245.

[69] F. K. Kleinbecker-Riniker, B. Martin, G. Penn, F. Venturoni, T. Schlama, T. Ruch, T. Allmendinger, B. Wietfeld, P. Filipponi, WO 2017/098430 Al, 2017.

[70] S. Novick, N. Dellas, O. Alvizo, D. Garcia, C. Ching, D. Entwistle, WO 2018/231462 Al, 2018.

[71] R. Ostafe, N. Fontaine, D. Frank, M. Ng Fuk Chong, R. Prodanovic, R. Pandjaitan, B. Offmann, F. Cadet, R. Fischer, Biotechnol. Bioeng. 2020, 117, 17, DOI: $10.1002 /$ bit.27169.

[72] L. Zhang, J. Tan, D. Han, H. Zhu, Drug Discov. Today 2017, 22, 1680, DOI: 10.1016/j.drudis.2017.08.010.

\section{License and Terms}

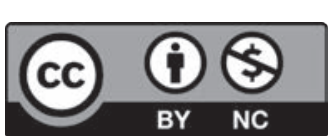

This is an Open Access article under the terms of the Creative Commons Attribution License CC BY_NC 4.0. The material may not be used for commercial purposes.

The license is subject to the CHIMIA terms and conditions: (http:// chimia.ch/component/sppagebuilder/?view=page \&id=12).

The definitive version of this article is the electronic one that can be found at doi:10.2533/chimia.2020.368 